\title{
Use of cuprous thiocyanate as a short-term continuous marker for faeces
}

\author{
MATTHEW DICK \\ From the Metabolic Unit, University College Hospital, London
}

The main technical difficulty in the use of insoluble markers for faeces such as chromium sesquioxide (Whitby and Lang, 1960) or barium sulphate (Dick, 1967) is in the solubilization of these very inert compounds. Digestions with perchloric acid or chelations with EDTA are time-consuming procedures. Accordingly a search has been made for a compound which although insoluble under physiological conditions, could be decomposed by relatively mild chemical treatment.

Cuprous thiocyanate (CuSCN) is a compound which has solubility characteristics in water rather similar to those of barium sulphate. In neutral or mildly alkaline conditions the solubility is about $0.5 \mathrm{mg} \%\left(\mathrm{BaSO}_{4} 0.25 \mathrm{mg} \%\right)$ and in $0.1 \mathrm{~N} \mathrm{HCl}$ about $3 \mathrm{mg} \%\left(\mathrm{BaSO}_{4} 1 \mathrm{mg} \%\right)$. Cuprous thiocyanate is, however, readily decomposed by $50 \%$ nitric acid at room temperature, or by $10 \%$ nitric acid at the boiling point. Thus to estimate $\mathrm{CuSCN}$ in faeces it is only necessary to add nitric acid, boil and filter, in order to obtain a solution for analysis of copper. This may be estimated by conventional chemical methods, or more simply, by atomic absorption spectroscopy.

\section{MATERIALS AND METHODS}

PREPARATION OF CuSCN Since at the beginning of this study no pure sample of CuSCN was available commercially, it was necessary to prepare such a compound. In doing so we have used the well tried gravimetric method of estimation of copper as CuSCN, reasoning that this would give a pure preparation (Vogel, 1961).

Copper sulphate ( $\mathrm{CuSO}_{4} \cdot 5 \mathrm{H}_{2} \mathrm{O} \mathrm{AR}$ ), $200 \mathrm{~g}$, is dissolved in about 3 litres of water with a few millilitres of concentrated $\mathrm{HCl}$ and brought to the boiling point. About $50 \mathrm{ml}$ of saturated sulphurous acid (prepared from $\mathrm{Na}_{2} \mathrm{SO}_{3} \cdot 7 \mathrm{H}_{2} \mathrm{O}$ AR and $\mathrm{HCl}$ ) is added and mixed and then $10 \% \mathrm{KSCN}$ AR is added slowly with stirring. Further portions of sulphurous acid are added from time to time to maintain reducing conditions. The $\mathrm{KSCN}$ is added until CuSCN is no longer precipitated. The precipitate should be white and the supernatant colourless and smelling of sulphur dioxide. The CuSCN is then filtered (Green's Hydruro $904 \frac{1}{2}$ is suitable) and washed well with distilled water until the filtrate is free from
$\mathrm{SO}_{4}\left(\mathrm{BaCl}_{2}\right.$ test). The pure $\mathrm{CuSCN}^{1}$ is then dried in an oven at $120^{\circ} \mathrm{C}$, powdered in a mortar, and weighed out into gelatin capsules.

ORAL ADMINISTRATION OF CUSCN AND COLLECTIONS OF SAMPLES For reasons which will be discussed under Toxicology, three different levels of oral CuSCN were used: $1 \mathrm{~g}, 500 \mathrm{mg}$, and $250 \mathrm{mg}$ per day. The lower the oral dose, the greater will become the interference from dietary copper. On normal diets faecal copper is of the order of 1 to $2 \mathrm{mg}$ per day; thus with an oral dose of $250 \mathrm{mg} \mathrm{CuSCN}$ the likely error from dietary copper will be up to about $1.5 \%$. This would not represent a serious error in fat estimations.

All daily doses were weighed out (to less than $1 \%$ error) and packed in three gelatin capsules, no. 2 for the $1 \mathrm{~g}$ dose and no. 4 capsules for the smaller doses. One capsule was then given with each of the three main daily meals.

Our general method for faecal fat collections is to start the patient on CuSCN, either 250 or $500 \mathrm{mg}$ per day, and at the same time give a single carmine marker. Two days after the carmine marker is passed one or more faecal specimens are obtained and delivered to the laboratory for estimation of fat and copper, the oral CuSCN then being terminated. In this procedure the patient is usually on oral CuSCN for less than one week.

ESTIMATION OF COPPER IN FAECES The simplicity of this method is due to the ease with which the copper compounds present are decomposed by dilute nitric acid at the boiling point. Filtration and washing then yield a solution suitable for analysis of copper, the results of which are expressed here in terms of CuSCN.

A faecal homogenate of the sample is made as in the faecal fat method of van de Kamer, Huinink, and Weyers (1949). From this homogenate samples from 20 to $40 \mathrm{~g}$ are weighed out into a $250 \mathrm{ml}$ conical flask. Ten $\mathrm{ml}$ concentrated $\mathrm{HNO}_{3}$ is added, a filter funnel is placed in the neck of the flask, the contents are brought to the boiling point and allowed to simmer for 10 minutes. Some frothing occurs near the boiling point but this is seldom serious. The sides of the flask (and funnel if necessary) may be washed down with water and this is usually sufficient to prevent further frothing. The contents of the flask are then filtered through Whatman no. 54 paper

${ }^{1}$ Recently Messrs Koch-Light Laboratories Ltd have agreed to produce CuSCN to a puriss standard. The price will depend upon the demand for this compound. 
into a $250 \mathrm{ml}$ standard flask; the filter paper is well washed with water and the volume made up to the mark. Filtration with this grade of paper is generally very rapid; a small amount of fine material may pass through the filter but this should be of no consequence to subsequent analysis. This solution may be used directly for analysis or may be diluted to an appropriate concentration.

\section{CHEMICAL METHOD}

Many complexiometric methods are available for the estimation of copper. The only difficulty in this case is the yellow colour of the extract which might interfere with the photometry. It was found that at the dilution employed here interference was negligible using an alkaline extraction with amyl alcohol-ether mixture of the complex with sodium diethyldithiocarbamate. The method is essentially that described by Varley (1967) for the estimation of serum copper.

REAGENTS

1 Ammonia, SG 0.88

2 Sodium pyrophosphate, $6 \%$ solution in water

3 Sodium diethyldithiocarbamate, $200 \mathrm{mg} \%$ in water

4 Amyl alcohol-ether mixture, 1 to 1

5 Powdered anhydrous sodium sulphate $A R$

6 Stock standard CuSCN, $1 \mathrm{mg}$ per $\mathrm{ml}$ Weigh out $500 \mathrm{mg}$ CuSCN, dissolve in $10 \mathrm{ml}$ concentrated $\mathrm{HNO}_{3}$ and make up to $500 \mathrm{ml}$.

7 Working standards, 10 to $50 \mu \mathrm{g}$ per $\mathrm{ml}$ These are prepared by diluting 1 to $5 \mathrm{ml}$ of the stock standard to $100 \mathrm{ml}$.

Glass-distilled water is used throughout.

TECHNIQUE One $\mathrm{ml}$ of a suitable dilution (usually 1 in 10) of the acid extract is pipetted into a $20 \mathrm{ml}$ glassstoppered tube. To this is added 5 drops of ammonia and about $5 \mathrm{ml}$ of glass-distilled water. The contents are mixed and $1 \mathrm{ml}$ of $6 \%$ sodium pyrophosphate and $1 \mathrm{ml}$ sodium diethyldithiocarbamate are then added and mixed. Five ml of the amyl alcohol-ether mixture is then added, the tube is stoppered and well shaken for at least one minute. The organic layer is removed to a photometer cuvette, a little powdered anhydrous sodium sulphate added and mixed in order to dry, and the colour read at $440 \mathrm{~m} \mu$ against a suitable standard and blank treated in the same manner as the test. The calibration curve should be linear over the range quoted.

\section{ATOMIC ABSORPTION METHOD}

The introduction of atomic absorption spectroscopy has resulted in the simplification of many analytical methods for metals. A dilution of the acid extract is suitable for analysis by this method and the concentration of copper present is such that no difficulty should be experienced in obtaining good sensitivity. Accordingly it is not proposed to go into technical details of the method which are similar to those already described for copper (see for example 'Technical Data Sheets', Hilger and Watts Ltd'), but to mention specific points.

Nitric acid has been found to have a slight effect on ${ }^{1}$ The apparatus used in this work was supplied by Messrs Hilger and Watts Ltd and contained the $\mathrm{H} 1150$ atomic absorption unit. the estimation. In order to minimize this the standards should have approximately the same concentration of nitric acid as the dilution of the acid extract. Dilute standards may be made up from a stock standard $(1 \mathrm{mg} / \mathrm{ml})$ prepared by dissolving $\mathrm{CuSCN}$ in nitric acid, an additional volume of $\mathrm{HNO}_{3}$ being then added to each dilute standard in order to bring it to approximately the same concentration of $\mathrm{HNO}_{3}$ as in the acid extracts for analysis.

Interference from other substances likely to be present in faeces has been investigated, particularly the effects of $\mathrm{Ca}, \mathrm{P}, \mathrm{Mg}, \mathrm{Na}$, and $\mathrm{K}$. Neither in normal nor pathological conditions should there be any substantial degree of interference from these substances. Added evidence for lack of interference is given by the good correlation between results obtained by the chemical method and the atomic absorption method (Table I). However, due to the technical simplicity, atomic absorption is the method of choice, and this method was used in most of the work quoted in this paper.

\section{RESULTS}

RECOVERIES OF CUSCN FROM FAECES When on four separate occasions $\mathrm{CuSCN}$ in the usual quantity was added to stools before homogenization, and the described methods followed, the recoveries of CuSCN were found as in Table I.

\section{TABLE I}

PERCENTAGE RECOVERIES OF CUSCN ADDED TO STOOLS

\begin{tabular}{rc} 
Atomic Absorption & Chemical \\
\hline 100 & 102 \\
103 & $100 \cdot 5$ \\
100 & $99 \cdot 5$ \\
102 & $99 \cdot 5$ \\
Means 101 & 100
\end{tabular}

The total copper recovery in faeces (calculated as $\mathrm{CuSCN}$ ) over 79 four-day balance periods on 14 human subjects on $1 \mathrm{~g} \mathrm{CuSCN}$ per day from the first carmine marker to the last was $99.7 \%$ of the CuSCN administered. The minimum number of four-day periods was three and the maximum nine. The minimum recovery in any individual was $97.0 \%$ and the maximum $102.8 \%$. A histogram of the recoveries and a comparison with those using $\mathrm{BaSO}_{4}$ (Dick, 1967) and $\mathrm{Cr}_{2} \mathrm{O}_{3}$ (Rose, 1964) are shown in Figure 1.

TOXICITY The first consideration with a compound of this type is of course the possibility of toxicity from absorption of either copper or thiocyanate, and these will be dealt with separately.

Experiments on the human adult began with the 


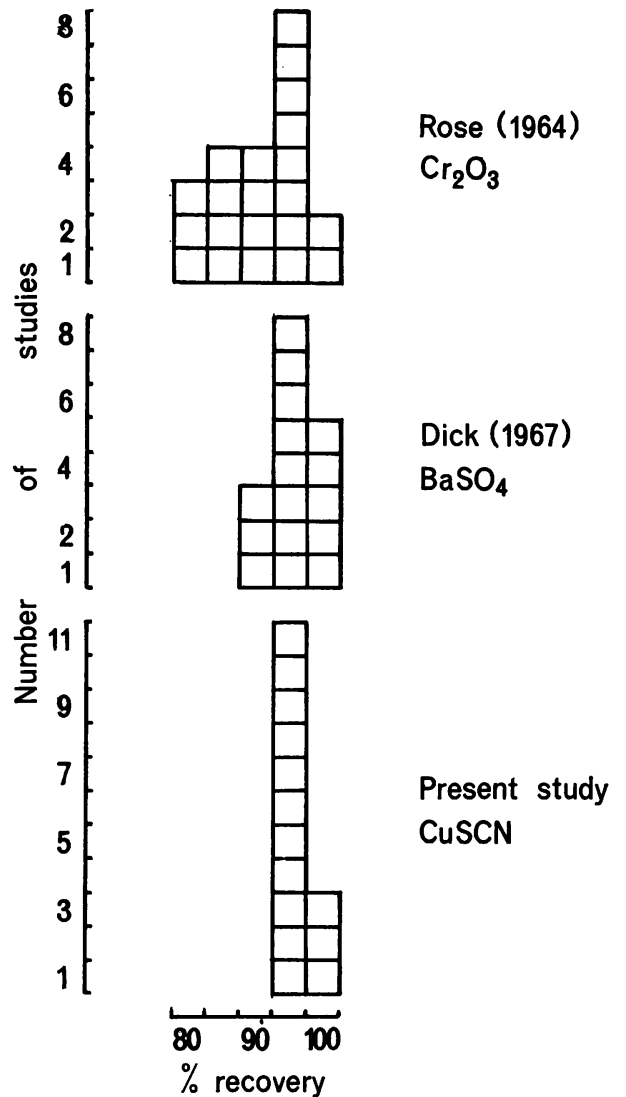

FIG. 1. Histograms of overall recoveries.

author taking small oral doses of the compound; first $30 \mathrm{mg}$, then five days later $300 \mathrm{mg}$, and eventually $1 \mathrm{~g}$. Blood copper levels (Varley, 1967) were estimated before and one, three, five, eight, and 24 hours after each dose. Copper oxidase activity (Ravin, 1961) was also estimated on all the latter specimens. Twenty-four-hour urines were collected and analysed for copper (Varley, 1967). In no case was there any significant change in copper or copper oxidase from the control samples, and no clinical symptoms were experienced. In the case of the $1 \mathrm{~g}$ dose an attempt was made to recover the copper from the subsequent stools and this is shown in Table II. It might be argued that $20 \mathrm{mg} \mathrm{CuSCN}$ remains to be accounted for, but under the experimental conditions involved in analysing separate stools, a recovery of $98 \%$ is very reasonable.

The author then undertook a trial of this compound as a continuous marker under metabolic conditions, taking $1 \mathrm{~g}$ per day split into four doses. After a run-up period of four days, five four-day
TABLE II

CUSCN RECOVERIES (INDIVIDUAL STOOLS) FROM $1 \mathrm{~g}$ CUSCN GIVEN ON FIRST DAY

\begin{tabular}{lc} 
Stools & $\begin{array}{l}\text { Recovery of } \\
\text { CuSCN } \\
(\mathrm{mg})\end{array}$ \\
\hline 1st day & - \\
2nd day & 559 \\
3rd day & 169 \\
4th day & 132 \\
5th day & 93 \\
5th day (2nd stool) & 27 \\
6th day $\quad$ Total recovery & 980
\end{tabular}

stool collections were made with carmine markers between all four-day periods. The recovery of copper (expressed as CuSCN) between the first and last carmine marker was $19.87 \mathrm{~g}$ or $99.4 \%$ of the intake. No change occurred in the blood copper, copper oxidase, or urine copper over this period.

The compound was then used as a continuous marker for faecal fat estimations over short periods of four or five days on patients on the metabolic ward. Plasma copper estimations done from time to time showed no changes and no symptoms attributable to copper toxicity were experienced. Later CuSCN was used as a continuous marker of $1 \mathrm{~g}$ per day in 14 human subjects on metabolic balance. In the 79 four-day periods involved, $99.7 \%$ of the administered copper was recovered between the first and last carmine markers. The compound has now also been used in over 100 patients for estimating short-term fat outputs without encountering any difficulty due to copper toxicity. Our experience, and especially the results of recovery experiments, leads us to believe that copper is not absorbed from this compound in human subjects on a normal diet.

When, however, tests were made for thiocyanate it became apparent that this radical is invariably present in plasma and urine in human subjects on oral $\mathrm{CuSCN}$, and that the plasma thiocyanate level varies considerably in different individuals on the same dose. Plasma thiocyanate was estimated by the method of Bowler (1944) modified for the AutoAnalyzer (unpublished). Figure 2 shows an average response to $1 \mathrm{~g} \mathrm{CuSCN}$ per day and also the highest levels we have seen over 10 days on this dose. The toxicology of this radical has been extensively studied in the past when thiocyanate was widely used in the treatment of hypertension and it is evident that levels of this magnitude would be unacceptable in patients. It is generally considered that the upper limit of safety is about 12 to $15 \mathrm{mg} \%$ of thiocyanate (Beckman, 1958; Sollmann, 1957).

With lower oral doses of CuSCN plasma levels of thiocyanate are also reduced. Thus with $0.5 \mathrm{~g}$ 


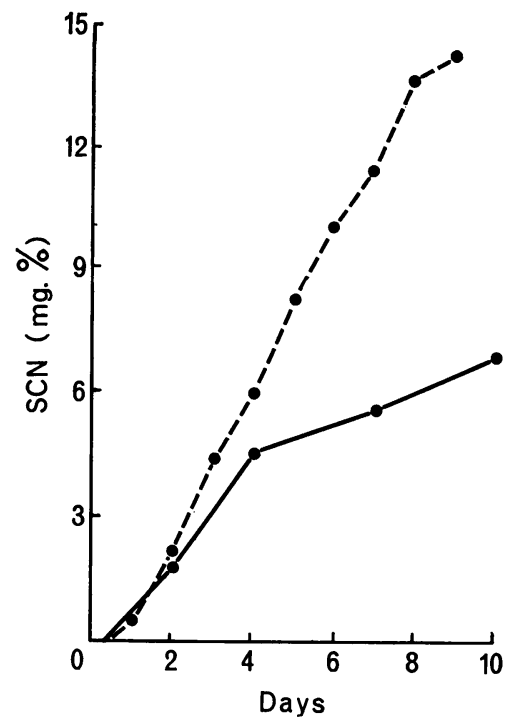

FIG. 2. Plasma SCN levels in human subjects on $1 \mathrm{~g} \mathrm{CuSCN}$ od.

- - - 'extreme' response.

'average' response.

per day average plasma values are about $4 \mathrm{mg} \%$ after seven days, while Fig. 3 shows the plasma levels in 20 individuals taking $250 \mathrm{mg}$ per day for seven days. The mean plasma value here after seven days was $2.6 \mathrm{mg} \%$. Over longer-term administration of a constant dose of CuSCN plasma levels of thiocyanate tend to stabilize. In general a dose of $1 \mathrm{~g}$ per day leads to values of about 10 to $20 \mathrm{mg} \%$, $0.5 \mathrm{~g}$ per day to levels of about 5 to $10 \mathrm{mg} \%$, and $0.25 \mathrm{~g}$ to levels of 2 to $5 \mathrm{mg} \%$.

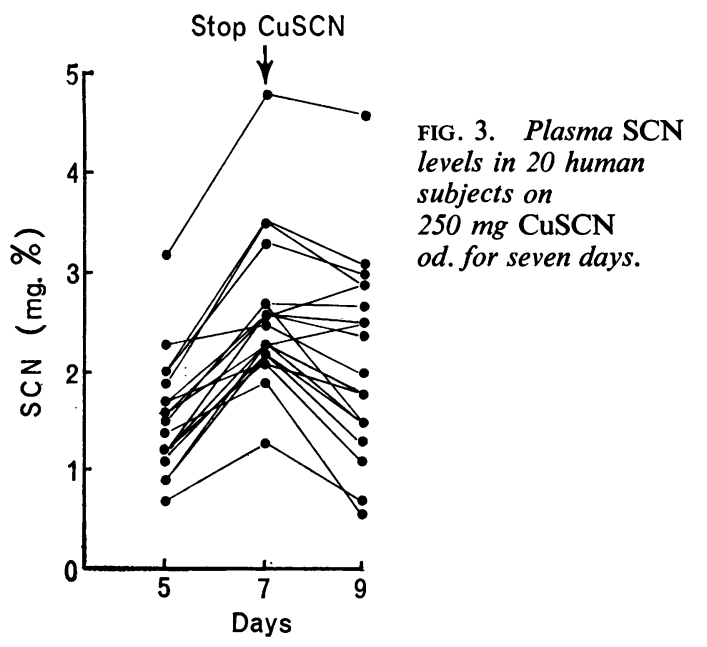

The passage of CuSCN through the gut thus results in a quantitative excretion of the copper in the faeces, but with a variable absorption of the thiocyanate radical. This is an unexpected finding in terms of gut $p \mathrm{H}$ as CuSCN is unaffected by the physiological range, ie, from $0 \cdot 1 \mathrm{~N} \mathrm{HCl}$ to $p \mathrm{H} \mathrm{9:}$ an active physiological process must be involved.

At much higher $p \mathrm{H}$ values, $e g$, with $0 \cdot 1 \mathrm{~N}$ $\mathrm{NaOH}, \mathrm{CuSCN}$ is hydrolysed to cuprous oxide $\left(\mathrm{Cu}_{2} \mathrm{O}\right)$

$$
2 \mathrm{CuSCN}+\mathrm{H}_{2} \mathrm{O} \longrightarrow \mathrm{Cu}_{2} \mathrm{O}+2 \mathrm{HSCN}
$$

The presence of a reddish compound in the faeces of human subjects on oral CuSCN supports the hypothesis that some reaction of this type occurs in the gut. We have so far been unable to prove this by analysis of the reddish compound, as the task of separating it in a pure state from faeces is formidable in the presence of food residues and of unchanged $\mathrm{CuSCN}$ (which is visible as a white powder).

Experiments suggest that protein, and by implication amino acids, are concerned in the splitting of CuSCN in the gut. While glycine itself, and also a mixture of 18 common amino acids, chelates copper from CuSCN very slowly and to a limited extent in vitro, the introduction of a low protein diet to a human volunteer on CuSCN results in an immediate fall in the plasma thiocyanate level (Fig. 4). Human duodenal juice does not by itself split CuSCN in vitro. Sterilization of the gut by neomycin produces a small fall in plasma thiocyanate, suggesting that the gut flora may be involved to some extent; however, this fall might be a non-specific malabsorption affect due to the neomycin. It would thus seem that $\mathrm{CuSCN}$ is partly converted to $\mathrm{Cu}_{2} \mathrm{O}$ in the gut by some active process involving protein or amino acids.

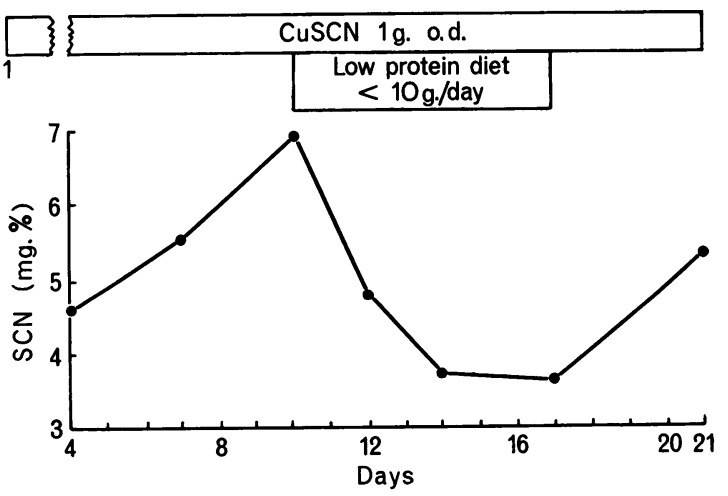

FIG. 4. Effect of a low protein diet ( $<10 \mathrm{~g} /$ day) on plasma $\mathrm{SCN}$ in a human subject on $1 \mathrm{~g} \mathrm{CuSCN}$ od. 


\section{DISCUSSION}

This compound provides a new approach to the problems of faecal marking. CuSCN starts its transit as a compound insoluble in stomach acid, but is presumably partially changed lower in the gut to a compound $\left(\mathrm{Cu}_{2} \mathrm{O}\right)$ insoluble under neutral or alkaline conditions. (It should be mentioned that $\mathrm{Cu}_{2} \mathrm{O}$ itself would be unsuitable as a marker as it is appreciably soluble in acid.)

The simplicity of estimating the compound in faeces is especially useful in such short-term studies as fat outputs. It has become evident that three- or five-day faecal collections without a continuous marker can be quite erroneous. Penfold (1967) states that 'there is reason to believe that of 1,085 faecal fat determinations which we have carried out during the past three years, the collections may have been incomplete or unrepresentative in as many as $30 \%$ of the cases'. Hitherto most laboratories have been deterred from using conventional markers such as $\mathrm{Cr}_{2} \mathrm{O}_{3}$ or $\mathrm{BaSO}_{4}$ due to the considerable labour involved. With CuSCN the laboratory labour is much reduced; indeed it is simpler to estimate faecal copper (in this quantity) than faecal fat. In addition it is possible to estimate faecal fat accurately on an outpatient basis with only a relatively small sample of stool sent to the laboratory.

The absorption of thiocyanate from the compound is a distinct disadvantage. However, the toxicology of thiocyanate has been thoroughly studied in the past and we consider that with doses not greater than $500 \mathrm{mg}$ per day over a limited time, there is very little possibility of a toxic reaction. This will be discussed in greater detail in a subsequent paper dealing with the clinical evaluation of the method. It should perhaps be emphasized that although for experimental reasons we have employed doses of $1 \mathrm{~g}$ per day for extended periods (up to 38 days) without serious toxic reactions, we do not recommend this practice without control by estimating plasma thiocyanate.

This work was supervised by Professor C. E. Dent. I am also deeply grateful to Dr Lyal Watson for help and encouragement during all stages of the project. Thanks are also due to all the volunteers who took the compound, especially the dietitian, Miss M. Bethel, and to the nursing staff of the Metabolic Unit.

\section{REFERENCES}

Beckman, H. (1958). Drugs: Their Nature, Action and Use. Saunders, Philadelphia and London.

Bowler, R. G. (1944). The determination of thiocyanate in blood serum. Biochem. J., 38, 385-388.

Dick, M. (1967). Use of barium sulphate as a continuous marker for faecss. J. clin. Path. 20, 216-218.

Kamer, J. H. van de, Huinink, H. ten Bokkel, and Weyers, H. A. (1949). Rapid method for the determination of fat in feces J. biol. Chem., 177, 347-355.

Penfold, W. A. F. (1967). Serum lipid levels following a fatty meal as a test of steatorrhoea. Proc. Ass. clin. Biochem., 4, 205-209.

Ravin, H. A. (1961). An improved colorimetric enzymatic assay of ceruloplasmin. J. Lab. clin. Med., 58, 161-168.

Rose, G. A. (1964). Experiences with the use of interrupted carmine red and continuous chromium sesquioxide marking of human faeces with reference to calcium, phosphorus, and magnesium. Gut, 5, 274-279.

Sollmann, T. (1957). A Manual of Pharmacology, 8th ed. Saunders, Philadelphia and London.

Varley, H. (1967). Practical Clinical Biochemistry, 4th ed. Heinemann, London.

Vogel, A. I. (1961). A Text-book of Quantitative Inorganic Analysis, 3rd ed. Longmans, London.

Whitby, L. G., and Lang, D. (1960). Experience with the chronic oxide method of fecal marking in metabolic balance investigations on humans. J. clin. Invest., 39, 854-863. 